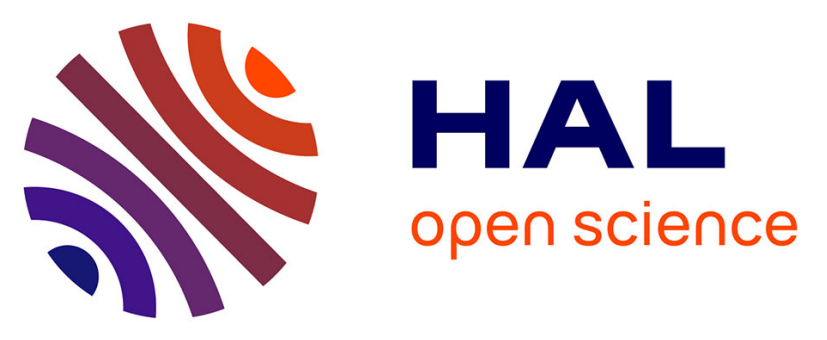

\title{
Towards an innovative combined process coupling biodegradation and photo-oxidation for the removal of pharmaceutical residues
}

Claire Joannis-Cassan, Alfredo S Rodriguez Castillo, Chloé Dezani, Cristian Gómez-canela, Brice Reoyo-prats, Carole Calas-blanchard, Carlos Barata, Silvia Lacorte, Gael Plantard

\section{To cite this version:}

Claire Joannis-Cassan, Alfredo S Rodriguez Castillo, Chloé Dezani, Cristian Gómez-canela, Brice Reoyo-prats, et al.. Towards an innovative combined process coupling biodegradation and photooxidation for the removal of pharmaceutical residues. Journal of Chemical Technology and Biotechnology, 2021, 96 (3), pp.755 - 763. 10.1002/jctb.6589 . hal-03451090

\author{
HAL Id: hal-03451090 \\ https://hal.science/hal-03451090
}

Submitted on 26 Nov 2021

HAL is a multi-disciplinary open access archive for the deposit and dissemination of scientific research documents, whether they are published or not. The documents may come from teaching and research institutions in France or abroad, or from public or private research centers.
L'archive ouverte pluridisciplinaire HAL, est destinée au dépôt et à la diffusion de documents scientifiques de niveau recherche, publiés ou non, émanant des établissements d'enseignement et de recherche français ou étrangers, des laboratoires publics ou privés. 


\section{Journal of \\ Chemical Technology and Biotechnology}

\section{Towards an innovative combined process coupling biodegradation and photo-oxidation for the removal of pharmaceutical residues}

\begin{tabular}{|c|c|}
\hline Journal: & Journal of Chemical Technology \& Biotechnology \\
\hline Manuscript ID & JСТВ-20-0440 \\
\hline Wiley - Manuscript type: & Research Article \\
\hline $\begin{array}{r}\text { Date Submitted by the } \\
\text { Author: }\end{array}$ & 04-Jun-2020 \\
\hline Complete List of Authors: & $\begin{array}{l}\text { Joannis-Cassan, Claire; Laboratoire de Génie Chimique, INP-ENSIACET } \\
\text { Rodriguez-Castillo, Alfredo Santiago; Laboratoire de Génie Chimique, } \\
\text { INP-ENSIACET } \\
\text { DEZANI, Chloé; PROMES, UPVD } \\
\text { GOMEZ CANELA, Cristiano; IDAEA, Department of Environmental } \\
\text { Chemistry } \\
\text { REOYO-PRATS, Brice; PROMES, UPVD } \\
\text { Calas-Blanchard, Carole; UPVD, Biocapteur-Analyse-Environnement } \\
\text { BARATA, Carlos; IDAEA, Department of Environmental Chemistry } \\
\text { Lacorte, S; IDAEA, Department of Environmental Chemistry } \\
\text { Plantard, G.; PROMES, UPVD }\end{array}$ \\
\hline Key Words: & $\begin{array}{l}\text { Photocatalysis, Pharmaceuticals, Bioreactors, Waste-Water, Removal, } \\
\text { Process Intensification }\end{array}$ \\
\hline
\end{tabular}

\section{SCHOLARONE ${ }^{\text {m }}$ Manuscripts}


1 Towards an innovative combined process coupling biodegradation and photo-oxidation for the 2 removal of pharmaceutical residues

3 Claire Joannis-Cassan ${ }^{1, *}$, Alfredo Santiago Rodriguez Castillo ${ }^{1}$, Chloé Dezani², Cristiano Gómez-

4 Canela $^{5}$, Brice Reoyo Prats ${ }^{2}$, Carole Calas-Blanchard ${ }^{3,4}$, Carlos Barata $^{5}$, Silvia Lacorte ${ }^{5}$, Gaël Plantard $^{2}$

$5 \quad{ }^{1}$ Laboratoire de Génie Chimique, Université de Toulouse, CNRS, INPT, UPS, France

$6{ }^{2}$ Laboratoire PROcédés, Matériaux et Energie Solaire, PROMES-CNRS UPR8521, Rambla de la

7 Thermodynamique, Tecnosud, 66100 Perpignan, France

$8{ }^{3}$ Université de Perpignan Via Domitia, Biocapteur-Analyse-Environnement, 66860 Perpignan cedex 9 France

$10{ }^{4}$ Laboratoire de Biodiversité et Biotechnologies Microbiennes, USR 3579 Sorbonne Universités 11 (UPMC) Paris 6 et CNRS Observatoire Océanologique, 66650, Banyuls-sur-Mer, France

${ }^{5}$ IDAEA-CSIC, Department of Environmental Chemistry, Jordi Girona 18-26, 08034 Barcelona, Catalonia, Spain

* Corresponding author : Claire Joannis-Cassan, Laboratoire de Génie Chimique, 4 allée Emile Monso, 17 CS 84234, F-31432 Toulouse cedex4, France. Email: claire.joanniscassan@ensiacet.fr, +33(5) 343236 
1 Abstract

2 BACKGROUND: Occurrence of pharmaceutical compounds in wastewater has become a major concern

3 for human health and the environment. Therefore, it is challenging to improve the conventional

4 wastewater treatment to remove these compounds. Coupling a biological treatment with an advanced

5 oxidation technology has been widely studied in the literature, but only sequential associations of the

6 two processes have been used. This study proposes an innovative concept based on a real integration of

7 the photocatalytic oxidation process in a continuous recycling loop on a membrane bioreactor. The role

8 of the oxidation is not here to completely degrade pharmaceuticals, but to oxidize them moderately to

9 increase their biodegradability so that they can be eliminated by the biological process.

RESULTS: Preliminary experiments on oxidation process indicated that a flux density of $5 \mathrm{~W} \cdot \mathrm{m}^{-2}$ was sufficient to increase biodegradability and decrease toxicity of a cocktail of 3 pharmaceuticals. Then performances of a $20-\mathrm{L}$ continuous membrane bioreactor treating wastewater with 7 pharmaceuticals, without and with pre-oxidation at $5 \mathrm{~W} \cdot \mathrm{m}^{-2}$ were compared. Pre-oxidation has increased the global removal for some recalcitrant pharmaceuticals (from 3 to $47 \%$ for diclofenac and for 1 to $44 \%$ for furosemide) without affecting neither the removal of carbon, nitrogen and phosphorous by activated sludge neither the removal of already highly removed pharmaceuticals.

CONCLUSION: This work proves the feasibility and interest of the innovative concept of a continuous hybrid process coupling a photocatalytic oxidation process and a membrane bioreactor for the treatment of pharmaceuticals in wastewater, with a low cost and size.

Key words: membrane bioreactor, photocatalytic oxidation, micropollutants, pharmaceuticals, hybrid process, wastewater treatment

\section{Introduction}

In the last three decades, an increasing number of research papers have reported the presence of pharmaceutical compounds (PhCs) in almost all water bodies, including surface waters, ground water, seawater but also drinking water, at range from ng.L.-1 to mg.L ${ }^{-1}$ all around the world. ${ }^{1,2,3}$ European Union (EU) monitoring found diclofenac as the most common polar pharmaceutical in natural waters. ${ }^{4}$ Other 
molecules - such as sulfamethoxazole, gemfibrozil, atenolol, naproxen, propranolol, ibuprofen, etc. - were commonly found in the aquatic environment. ${ }^{5}$ Carbamazepine, an antiepileptic drug, was also frequently detected in groundwater and surface water. ${ }^{5,6}$ Pharmaceuticals have become one of most important class of emerging organic micropollutants since they are persistent and bioactive compounds that could affect aquatic organisms even at very low concentrations. ${ }^{1,3,6,7}$ Main source of pharmaceutical pollution in the environment comes from wastewater treatment plants (WWTP) effluents, mainly composed by domestic and industrial wastewaters but also receiving hospital or elderly house effluents which are released untreated to the sewage grid. ${ }^{1,3,8-10}$ Due to their intrinsic characteristics of high polarity and stability, most of $\mathrm{PhCs}$ are not removed by conventional activated sludge (CAS) in WWTP. ${ }^{2,3,5,7}$ They are consequently continuously released into the aquatic surfaces and their increasing occurrence has become a major environmental and human health concern. Membrane bioreactors (MBRs) have shown a higher efficiency than CAS in removing many pharmaceuticals due to longer sludge retention time and higher suspended solids that favor higher biodiversity and promote stability against high load variations. ${ }^{5,8}$ However, some pharmaceuticals remain poorly biodegraded even by MBR, including carbamazepine (CBZ) which is one of the most biorecalcitrant drug. ${ }^{2,5}$

To improve the removal efficiency of pharmaceutical compounds, coupling the biological treatment with complementary technologies including adsorption on activated carbon, membrane separation processes or advanced oxidation processes (AOP) have been studied. ${ }^{1,11-13}$ Contrary to the two first technologies that only consist in a phase-transfer of micropollutants, AOP could efficiently respond to the problem posed by biorecalcitrant drugs due to their ability to non-selectively degrade micropolluant molecules. ${ }^{14-16}$ Recent works have shown that AOP can significantly reduce effluent toxicity, increase biodegradability or allow mineralization of many molecules: pesticides, industrial products even at high concentrations ${ }^{17}$, but also pharmaceutical emerging residues at lower concentrations. ${ }^{15,16,18-21}$ With these considerations, AOPs could be used as a pre-treatment of biological processes in order to increase biodegradability of the pollutants or as a post-treatment in order to degrade the micropollutants not completely removed by the biological process. These different combinations have been recently reviewed for emerging contaminants in wastewater. ${ }^{1,5,20-25}$ It appears that AOP could be ineffective as a pre-treatment, due to the complexity of the wastewater matrix characterized by a high concentration of biodegradable compounds and very low 
1 concentration of the targeted micropollutants ${ }^{25}$. That is why most frequent combinations of

2 biological/advanced oxidation processes reported in the literature concern a biological step followed by

3 AOP such as ozonation, photo-Fenton or heterogeneous photocatalysis oxidation with $\mathrm{TiO}_{2} \cdot 1,5,22$

4 Nevertheless, formation of oxidation intermediates more toxic than the parent compounds may occur

5 depending on the applied conditions. ${ }^{11,22,24,25}$

6 Thus, this study aims to propose an innovative concept based on an effective integration of a biological

7 process and a AOP, in which AOP is placed in a continuous recirculation loop on the biological process

8 (Figure 1). The objective of the AOP is not a complete mineralization of the biorecalcitrant molecules, but

9 a moderate oxidation to increase their biodegradability in order they could be removed by the biological process. This hybrid process would intensify the biological one thanks to the synergetic effect of the two processes. A MBR has been chosen as biological process since it is more efficient for pharmaceutical removal and less sensitive to high load variation ${ }^{5}$. Among AOP, heterogeneous photocatalysis with $\mathrm{TiO}_{2}$, one on the most studied oxidation process, ${ }^{15,26}$ has been selected as it can be driven by solar radiation and so reduce costs and environmental impacts of the process. ${ }^{13}$

The main objective of this paper was to assess the feasibility and performance of this integrated system for the treatment of pharmaceutical micropollutants in wastewater. Three pharmaceuticals widely investigated in the literature: ibuprofen (IBU), diclofenac (DCF) and carbamazepine (CBZ) have been first selected as model molecules with high, moderate and low biodegradation potential respectively. Then, four additional molecules among the most frequently found in wastewater from retirement homes ${ }^{10}$ have also been added: furosemide (FUR), levetiracetam (LEV), amylmetacresol (AMY) and paracetamol (PAR). To demonstrate the feasibility of this hybrid system, this work was divided into two distinct steps. First, preliminary experiments were conducted on a continuous photo-oxidation process alone with the aim to determine the best oxidation conditions (flux density) that make the effluent biodegradable (Figure 1, experiment (2). Then, a 20L-MBR was operated in a continuous mode to treat first wastewater without oxidation (with native molecules) as a reference (Figure 1, experiment $\mathbf{0}$ ) and then an effluent previously oxidized with the optimal conditions (Figure 1, experiment (3). Carbon, nitrogen, phosphorous and pharmaceutical removal performances as well as effluent toxicity using Zebra fish as model organism were investigated. 
Material and methods

Pharmaceuticals. IBU, DCF, CBZ, FUR, AMY, LEV, PAR were purchased from Sigma-Aldrich (purity $>98 \%$ ). Stock solutions were prepared at concentration of $10 \mathrm{mg} \cdot \mathrm{L}^{-1}$ per compound. All solutions were prepared in ultrapure water ( $>17.5 \mathrm{~m} \Omega . \mathrm{cm}$ ) stored at $4{ }^{\circ} \mathrm{C}$ and used within one month.

Photo-oxidation reactor experiments. Based on a plan-type model configuration illustrated in Figure 2, the experimental setup is built of a continuous photoreactor running under controlled flow rate $(\mathrm{Q})$ and irradiated thanks to a panel of LEDs. ${ }^{27}$ The photo-reactor is a parallelepiped window (4) with a width of $10 \mathrm{~cm}$, a length of $15 \mathrm{~cm}$ and a thickness of $1 \mathrm{~cm}$. A plate of transparent PMMA UV radiation (90\%) is fixed to transmit radiation coming from the LEDs. The LED panel (5) is included in a closed chamber to isolate it from any external light source. The UV flux density (I) can be modulated between 1 and 110 W.m-2. A multi-channel peristaltic pump (Watson Marlow 205 CA) (1) feeds the photoreactor with continuous flow rate $\left(\mathrm{Q}=5 \mathrm{~mL} \cdot \mathrm{min}^{-1}\right)$ of the solution to be oxidized. A previously optimized concentration of 2 g.L.-1 of $\mathrm{TiO}_{2}$ was added in the solution. ${ }^{18}$ To ensure homogeneous distribution of the photocatalyst, the photo-reactor is connected to a $0.25 \mathrm{~L}$ recirculation loop system (2) thanks to a variable-speed centrifugal pump (Cole-Palmer Instruments) (3). In this way, the photoreactor runs as a continuous stirred tank reactor. Oxidized samples were taken at least 60 minutes after switch on the LED panel in order to be sure that the steady state was reached.

In the first part of this work, preliminary oxidation experiments were performed with IBU, DCF and CBZ - single or in cocktail - solutions at $10 \mathrm{mg} \cdot \mathrm{L}^{-1}$ in distilled or tap water. Several flux densities $(2 ; 5$; $10 ; 20$ and $40 \mathrm{~W} . \mathrm{m}^{-2}$ ) were tested. Other operating conditions such as flow rate (Q), $\mathrm{pH}$ and temperature were kept constant. Samples of oxidized solutions were taken for biodegradability, toxicity and micropollutant concentration measurements.

Then, photo-oxidation at $5 \mathrm{~W} \cdot \mathrm{m}^{-2}$ of $15 \mathrm{~L}$ of a solution containing all the studied pharmaceuticals (IBU, DCF, CBZ, FUR, AMY, LEV and PAR) in tap water at a concentration of $4.5 \mathrm{mg} \cdot \mathrm{L}^{-1}$ each, was performed. This solution was then diluted before being treated by the membrane bioreactor.

Membrane bioreactor experiments. A laboratory-scale MBR with a working volume of 20 L (Figure 3) was equipped with a Rushton turbine (200 rpm) and temperature, dissolved oxygen and $\mathrm{pH}$ probes. A membrane module consisted of a ceramic tubular Membralox ${ }^{\circledR}(\mathrm{MF})$ membrane with surface area of 
$10.0055 \mathrm{~m}^{2}$ and pore size of $0.2 \mu \mathrm{m}$ (Pall Exekia, France) was located in an external loop. The tangential

2 velocity in the membrane was set to $4 \mathrm{~m} \cdot \mathrm{s}^{-1}$. At initial time, the bioreactor was seeded with an activated

3 sludge from a real WWTP (Castanet-Tolosan, France) with a total suspended solids (TSS) concentration

4 of 2 g.L $L^{-1}$. Then, the MBR was continuously fed with a synthetic wastewater and permeate flowrate was

5 set to $10 \mathrm{~L} \cdot \mathrm{d}^{-1}(\mathrm{HRT}=48 \mathrm{~h})$. The synthetic wastewater was composed of peptone $\left(640 \mathrm{mg} . \mathrm{L}^{-1}\right)$, meat

6 extract (440 mg.L $\left.\mathrm{L}^{-1}\right), \mathrm{K}_{2} \mathrm{HPO}_{4}\left(28 \mathrm{mg} \cdot \mathrm{L}^{-1}\right), \mathrm{NaCl}\left(7 \mathrm{mg} \cdot \mathrm{L}^{-1}\right), \mathrm{CaCl}_{2}\left(16 \mathrm{mg} \cdot \mathrm{L}^{-1}\right), \mathrm{MgSO}_{4}\left(8 \mathrm{mg} \cdot \mathrm{L}^{-1}\right)$,

$7 \quad \mathrm{NH}_{4} \mathrm{Cl}\left(100 \mathrm{mg} . \mathrm{L}^{-1}\right)$ and $\mathrm{NaOAc}\left(80 \mathrm{mg} . \mathrm{L}^{-1}\right)$ diluted in tap water, corresponding to a chemical oxygen

8 demand (COD) of $1000 \mathrm{mg} \cdot \mathrm{L}^{-1}$, a total nitrogen (TN) content of $120 \mathrm{mg} \cdot \mathrm{L}^{-1}$ and a total phosphorous

9 (TP) content of $10 \mathrm{mg} \cdot \mathrm{L}^{-1} \cdot \mathrm{pH}$ was maintained at 7.2. Cycles of 3 min aeration (dissolved oxygen of 4.5 $\left.\mathrm{mg} \mathrm{O}_{2} \cdot \mathrm{L}^{-1}\right) / 30 \mathrm{~min}$ without aeration allowed aerobic / anoxic conditions for nitrification and denitrification steps. ${ }^{28}$ A part of activated sludge $(1 \mathrm{~L})$ was daily removed from the bioreactor to maintain sludge retention time (SRT) at $20 \mathrm{~d}$. Experiments were carried out in two phases: 15 days without addition of pharmaceuticals (Phase I), then 15 more days by adding micropollutant solution (Phase II). This micropollutant solution consisted in a cocktail of the seven native pharmaceuticals (IBU, CBZ, DCF, LEV, AMY, PAR, FUR at a concentration feeding of $40 \mu \mathrm{g} . \mathrm{L}^{-1}$ each) for the first campaign (MBR_1). For the second campaign (MBR_2), the same pharmaceutical cocktail was previously oxidized at $5 \mathrm{~W} \cdot \mathrm{m}^{-2}$ by the photoreactor before feeding the membrane bioreactor. For each campaign, samples of the feeding solution, membrane permeate, purge and mixed liquor were taken every two days at the end of the anoxic phase to be characterized (TSS, VSS, COD, TN, $\mathrm{NH}_{4}^{+}, \mathrm{NO}_{2}^{-}, \mathrm{NO}_{3}^{-}$). During phase II, adequate volume of permeate were also sampled every three days for pharmaceutical concentration quantification and once a week for toxicity measurement. All the samples were collected in $20 \mathrm{~mL}$ glass vials and were frozen at $-18^{\circ} \mathrm{C}$ until analysis.

Physicochemical characterization of wastewater. A $20 \mathrm{~mL}$ sample were centrifuged at 13,500 g during 15 min and supernatant was analyzed by means of $\mathrm{HACH}$ Kits. The parameters and corresponding HACH Kits were: Chemical Oxygen Demand (COD) (LCK 314 and LCK 514), Total Nitrogen (TN) (LCK 338), $\mathrm{NH}_{4}-\mathrm{N}$ (LCK 303 or LCK 301), $\mathrm{NO}_{2}-\mathrm{N}$ (LCK 341), $\mathrm{NO}_{3}-\mathrm{N}$ (LCK 340), Total Phosphorous (TP) (LCK 350). 
1 Sludge characterization. The concentrations of Total Suspended Solids (TSS) and Volatile Suspended

2 Solids (VSS) were measured according to standard methods 2540D and 2540E. ${ }^{29}$

3 Biodegradability assay. Biodegradability of micropollutant solution (pharmaceutical cocktail or oxidized pharmaceutical cocktail) was determined using biological oxygen demand $\left(\mathrm{BOD}_{28}\right)(\mathrm{OECD}$ $301)^{30}$ based on oxygen amount required by an activated sludge to metabolize micropollutants during 28 days. $\mathrm{BOD}_{28}$ was measured tanks to a respirometry apparatus (OxiTop C, WTW). Flasks were prepared in duplicate with mineral solution ${ }^{30}$ and either sample (S) or distilled water to measure endogenous respiration (ER) of sludge or a solution of glucose and glutamic acid ${ }^{30}$ for activity control of the activated sludge. Volume of mineral solution and sample were adjusted according to their COD concentration $^{30}$. Activated sludge came from the WWTP of Castanet Tolosan (France) and was inoculated, after washing three times with distilled water, at a final concentration of $0.05 \mathrm{~g}^{\mathrm{L}} \mathrm{L}^{-1}$. Biodegradability of micropollutant solution was expressed as a percentage of oxygen depletion relative to their COD concentration:

Biodegradability $(\%)=\frac{\mathrm{BOD}_{28}^{\mathrm{S}}-\mathrm{BOD}_{28}^{\mathrm{ER}}}{\mathrm{COD}}$ where $\mathrm{BOD}_{28}^{\mathrm{ER}}$ is measured in endogenous respiration flask and $\mathrm{BOD}_{28}^{\mathrm{S}}$ is the value of sample flask. Analysis of pharmaceuticals. Water samples were unfrozen the same day of the analysis. Samples from the MBR experiment were filtered through 0.22 nylon filters to remove particulate matter. Then, aliquots of this water were collected in chromatographic amber vials. For high concentrations, a dilution of 1/100 was performed in water. Liquid chromatography coupled to tandem mass spectrometry (LCMS/MS,TQD, Waters, Mildford, USA) was used for pharmaceutical analysis..$^{31}$ Drugs were measured under positive electrospray ionization (ESI+), except for ASP and FUR that were detected in negative electrospray ionization (ESI-). Chromatographic separation was performed using a Synergy Polar-RP column (250 mm x $4.6 \mathrm{~mm}$, particle size 4um, Phenomenex, Torrace, USA). The mobile phases were a binary mixture with $0.1 \%$ of formic acid in acetonitrile (A) and $0.1 \%$ formic acid in water (B). Gradient elution started at $10 \% \mathrm{~A}$, increasing to $70 \% \mathrm{~A}$ in 20 minutes and to $100 \%$ in 5 minutes, held for 7 minutes and returned to initial conditions after 3 minutes. The analysis run time was 35 minutes. Flow rate was set at $0.4 \mathrm{~mL} \cdot \mathrm{min}^{-1}$. Sample tray was maintained at $5^{\circ} \mathrm{C} .10 \mu \mathrm{L}$ of the sample were directly injected into the LC-MS/MS system. All data were acquired and processed using Masslynx v 4.1 software (Waters). 
1 Two MS/MS transitions were used to monitor each compound and for confirmation their ion ratios were

2 evaluated. Quantification was done using the most abundant transition. External standard calibration

3 was used to calculate the concentration of pharmaceuticals. The system was linear over the range $0.01-$

$42.5 \mathrm{ng} \cdot \mu \mathrm{L}^{-1}(\mathrm{R} 2>0.99)$ for all compounds. Compounds were efficiently recovered with the direct

5 injection analysis (from 69 to $117 \%$ ).

6 Toxicity assay. The procedure previously reported by Raldúa et al. (2008) $)^{32}$ with minor modifications

7 was followed. Embryos from wild type zebrafish were obtained by natural mating and maintained in

8 fish water [reverse-osmosis purified water containing $90 \mu \mathrm{g} \cdot \mathrm{mL}^{-1}$ of Instant Ocean (Aquarium Systems,

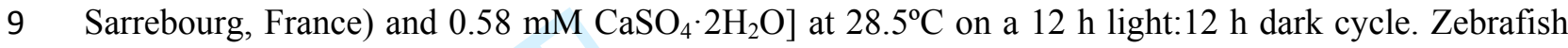
embryos were transferred to 48 -well microplates (1 larva per well) each well containing $1 \mathrm{~mL}$ of media, and exposed from 6 hpf to 120 hpf. 24 embryos were used for each condition. Viability of embryos was checked at 24, 48 and $120 \mathrm{~h}$. Dead embryos or malformations were reported as endpoints at the end of the experiment. All procedures were conducted in the animal facility of CID-CSIC in accordance with institutional guidelines under a license from the local government (agreement number 9027) and approved by the Institutional Animal Care and Use Committee. Water samples were kept frozen at $-20^{\circ} \mathrm{C}$ until toxicological analyses. Firstly range finding test were conducted to determine the optimal dilution to achieve mortalities in initial samples lower or closer to $100 \%$ but greater than $50 \%$. Then all samples were assayed at the dilution having the greater number of responses $(\leq 100 \%)$ across treatments. Samples were diluted using zebrafish water. Dilutions ranged from no dilution (x 1) to $1 / 16$.. CBZ alone did not produce embryotoxic effects in zebrafish at $10 \mathrm{mg} \cdot \mathrm{L}^{-1}$, thus this drug alone was not assayed. Each trial has a control with zebrafish water and the assay was considered valid if mortality (arrest or embryo malformation) in controls was $<5 \%$.

\section{Removal performance calculations.}

Performance of pollutants (COD, N, P) or pharmaceutical removal for both MBR and photo-oxidation processes were assessed with global removal efficiencies (RE), calculated as follow:

$$
\operatorname{RE}(\%)=\frac{\left(\mathrm{C}_{\mathrm{IN}}-\mathrm{COUT}_{\mathrm{T}}\right)}{\mathrm{C}_{\mathrm{IN}}}
$$


1 Where $\mathrm{C}_{\mathrm{IN}}$ and $\mathrm{C}_{\mathrm{OUT}}$ are the concentrations of the pollutants or pharmaceuticals in the inlet and outlet of

2 the processes. For MBR process, $\mathrm{C}_{\mathrm{OUT}}$ is the concentration in the permeate.

\section{Results and discussion}

\section{$4 \quad$ Photocatalytic experiments}

\section{$5 \quad$ Photo-oxidation of separate pharmaceuticals}

6 Constant operating conditions with a flux density fixed at $\mathrm{I}=10 \mathrm{~W} \cdot \mathrm{m}^{-2}$ were used to oxidize solutions 7 containing IBU, DCF and CBZ alone at $10 \mathrm{mg} \cdot \mathrm{L}^{-1}$. Figure 4.a presents the removal efficiency of 8 pharmaceutical photo-oxidation when molecules were oxidized separately. Different behaviors have 9 been observed depending on the molecules: photo-degradation varied from $12 \%$ for CBZ, which was the most resistant to oxidation up to $39 \%$ for IBU, which was the most sensitive to oxidation in these experimental conditions. These results confirm that degradation rate depends on the catalyst / molecule pair. ${ }^{18}$ Indeed, heterogeneous oxidation mechanism begins with mass transfer from the solution to the catalyst. Since pollutants can only be photo-degraded close to in catalyst surface, which is site of radical production, interactions between pollutant and catalyst are driven by physicochemical characteristics of both molecules (hydrophobicity) and solution (salinity, $\mathrm{pH}$, organic matter content). The impact of the oxidation on biodegradability of these 3 molecules can been seen on Figure 4.b. The biodegradability of CBZ and DCF was zero both before and after photo-oxidation, despite the efficiency of the oxidation process to reduce CBZ and DCF concentrations. It seems that DCF, CBZ and their oxidized transformation products could not be used or transform by activated sludge microorganisms in the conditions used for the biodegradability test. On the contrary, oxidation of DCF solution decreased its toxicity (Figure 4.c) indicating that oxidation transformation products seemed less toxic for the environment even if their could not be biodegraded in the tested conditions. Concerning IBU, its biodegradability before oxidation was quite high $(\sim 70 \%)$ and increased up to $83 \%$ after oxidation, probably due to the higher biodegradability of its oxidation products coupling with a toxicity divided by two after oxidation (Figure 4.c). These first results show the positive effect of the photo-oxidation at I $=10 \mathrm{~W} \cdot \mathrm{m}^{-2}$ on the biodegradability and toxicity of the three selected micropollutants.

\section{Cocktail effect on oxidation efficiency}


1 The same constant operating conditions with a flux density fixed at $\mathrm{I}=10 \mathrm{~W} \cdot \mathrm{m}^{-2}$ were applied on a

2 solution containing a cocktail of CBZ, DCF and IBU at an initial concentration of $10 \mathrm{mg} \cdot \mathrm{L}^{-1} \mathrm{each}$. When

3 in cocktail, the three pharmaceuticals were more recalcitrant to oxidation as photodegradation efficiency

4 varied between 1 and $5 \%$ (Figure 4.d). This could be due to competition phenomena between the

5 molecules and their byproducts on catalyst surfaces that strongly limit photodegradation rate. However,

6 despite the lower photodegradation, the biodegradability of the oxidized cocktail was quite the double

7 of the non-oxidized cocktail (Figure 4.e) and toxicity decreased by $60 \%$ (Figure 4.f). Even if they are

8 not well explained by the literature, synergetic effects between native molecules as well as photo-

9 oxidation products clearly influence their impact on living beings, as it can be observed with biodegradability and toxicity tests.

\section{Influence of flux density on DCF, IBU and CBZ cocktail}

Photo-oxidation experiments were then conducted with the cocktail of DCF, IBU and CBZ, at a concentration of $10 \mathrm{mg} \cdot \mathrm{L}^{-1}$ each, with different flux densities $\left(2 ; 5 ; 10 ; 20\right.$ and $\left.40 \mathrm{~W} . \mathrm{m}^{2}\right)$. Overall, the photodegradation removal efficiency (Figure 5.a) increased with the flux density. For DCF, that was the most sensitive to photo-oxidation in these conditions, photo-oxidation removal efficiency increased from 0 to $10 \mathrm{~W} \cdot \mathrm{m}^{-2}$ and seemed to stabilize for higher flux densities.

Biodegradability and toxicity of the oxidized solutions also depends on the applied flux density (Figure 5.b). Significant increase was observed for biodegradability until $5 \mathrm{~W} . \mathrm{m}^{-2}$. Above this flux density, biodegradability level was quite constant around a maximal value of $40 \%$. A higher biodegradability was linked to a lower toxicity. Indeed, toxicity decreased when flux density increased and stabilized was around $15 \%$. This demonstrates that photo-oxidation allows to increase the biodegradability of the pharmaceutical solution while reducing its toxicity in the tested conditions. Besides, an increasing the flux density above $5 \mathrm{~W} \cdot \mathrm{m}^{-2}$ does not improve significantly this biodegradability. Thus, with the objective to couple photo-oxidation step with a biological treatment, a flux density value of $5 \mathrm{~W} \cdot \mathrm{m}^{-2}$ was selected to oxidize a synthetic wastewater before its treatment by a membrane bioreactor

\section{Membrane Bioreactor experiments}

\section{Biological treatment of non-oxidized pharmaceuticals}


As a reference, the 20-L membrane bioreactor experiment (MBR_1) was performed in a continuous mode to treat a synthetic wastewater containing seven micropollutants frequently detected at the outlet of retirement homes (IBU, DCF, CBZ, LEV, AMY, PAR, FUR) at concentration of $40 \mu \mathrm{g} . \mathrm{L}^{-1} \mathrm{each}$ (Figure 1- Experiment ( ). These pharmaceuticals were added in the synthetic wastewater after a first stage of stabilization of the biological process without pharmaceutical addition. Table 1 summarizes the sludge characteristics and the carbon, nitrogen and phosphorous removal efficiencies before (phase I) and after (phase II) addition of the pharmaceuticals. As can be seen, pharmaceutical addition had little impact on MBR running, excepted for nitrogen removal, which was higher after the addition of the micropollutants. This could be due to a longer adaption time needed to nitrifying biomass to be efficient rather than micropollutant addition. Indeed, before spiking with pharmaceuticals, $\mathrm{NH}_{4}^{+}$concentration in permeate was about $25 \mathrm{mg} . \mathrm{L}^{-1}$ at the beginning of the experiment and decreased to $6 \mathrm{mg} . \mathrm{L}^{-1}$ after 15 days of running which correspond to the time of micropollutant addition. However, nitrogen removal was limited by the denitrification step as a concentration of $\mathrm{NO}_{3}^{-}$in permeate was between 30 and 50 mg. $\mathrm{L}^{-1}$ all along the experiment. This limited impact of native pharmaceutical compounds on COD and TN removal has been often reported in the literature for several pharmaceuticals ${ }^{33}$. Only in some studies dealing with high concentration of antibiotics, a decrease in denitrification step was observed. ${ }^{34,35}$ To go further in comprehension, pharmaceutical apparent removals in continuous MBR are reported in Table 2. Three molecules (IBU, PAR, AMY) were highly removed ( $>70 \%$ ) by the activated sludge, one (LEV) was moderately removed (between 30 and $70 \%$ ) and the other three (DCF, CBZ, FUR) were poorly removed $(<30 \%)$. For CBZ, apparent removal was negative due to poor biodegradability and possible accumulation in MBR. ${ }^{5}$ This behavior has already been observed in CAS or MBR for the treatment of real effluent and could be explained by the inflow of pharmaceuticals in the conjugated form that are transformed into the original compounds during treatment. ${ }^{33}$ For IBU, DCF, CBZ and PAR, the apparent removal efficiencies are in the range of those reported in the literature for $\mathrm{MBR}$ experiments (Table 2). ${ }^{5,37-39}$ For FUR removal, only two papers were found, ${ }^{38,39}$ so the comparison with literature should be done with care. To our best knowledge, removal efficiencies in MBR have never been reported before for LEV and AMY. As CBZ, FUR and DCF were poorly biotranformed, coupling of the MBR with the photo-oxidation process is of great interest for global removal of these molecules. 
2 A second MBR experiment (Figure 1- Experiment

\section{Biological treatment of oxidized pharmaceuticals} follow:

$$
\mathrm{RE}_{\mathrm{OX}+\mathrm{MBR} \_2}(\%)=\mathrm{RE} \mathrm{OX}_{+}+\left(1-\mathrm{RE}_{\mathrm{OX}}\right) \cdot \mathrm{RE}_{\mathrm{MBR} \_2}
$$

\section{3)}

same conditions as MBR_1 experiment except that pharmaceutical solution was previously oxidized at 5 W.m-2 (Figure 1- Experiment (2). As for MBR_1, pre-oxidized pharmaceuticals were added after a stage of 15 days without drug supply. As for native pharmaceuticals, no significant difference was observed between the two phases (Table 1). This result is promising since feeding MBR with the oxidized solution did not impact its global removal performances in terms of carbon, nitrogen or phosphorous. Besides pre-oxidation of the pharmaceutical solution at $5 \mathrm{~W} \cdot \mathrm{m}^{-2}$ seems to affect positively the removal of the selected pharmaceuticals. Indeed, considering the MBR performance alone (Table 2 /MBR_2), when the pharmaceutical cocktail has been pre-oxidized at $5 \mathrm{~W} . \mathrm{m}^{-2}$, apparent removal increased for DCF, FUR and LEV. Molecules already highly biodegraded in MBR_1, maintain their high removal efficiency. Only CBZ removal remained negative. These results are in agreement with the increased of biodegradability observed above and the lower toxicity of the effluent. By focusing on preoxidation, a slight decrease was observed in concentrations of the parent compound, corresponding to removal efficiencies ranging from $0 \%$ for FUR up to $36 \%$ for PAR (Table 2/Oxidation), as well as a decrease in toxicity from $15 \pm 3 \%$ before oxidation to $0 \%$ after oxidation. This could increase the biodegradability of the oxidized solution as previously observed for the cocktail of IBU, DCF and CBZ at higher concentration and so decrease the potential negative impact on sludge. Removal efficiencies of the oxidation / MBR combination reported in Table 2 (Oxidation + MBR_2) were calculated as

For all pharmaceuticals, removal efficiency increased with addition of the oxidation step comparing to MBR alone (MBR_1). Thus flux density of $5 \mathrm{~W} \cdot \mathrm{m}^{-2}$ was enough to improve the biodegradation of the selected pharmaceuticals by MBR without changing its performance of wastewater treatment. This result validates the feasibility of the concept described in Figure 1 of coupling a MBR with a photooxidation process. A higher removal performance for the less degraded molecules (DCF, CBZ and FUR) 
1 is expected with the continuous coupling of the two processes since continuous recirculation in the

2 photo-oxidation process will generate several oxidation/biodegradation cycles.

\section{Conclusion}

4 The concept of coupling in one process, a biological treatment by a MBR and a photo-oxidation process 5 has been proven for the treatment of pharmaceuticals in wastewater. A flux density of 5 W.m $\mathrm{m}^{-2} \mathrm{was}$

6 sufficient to improve the removal of most of the selected pharmaceuticals by a MBR without changing

7 its performance in carbon, nitrogen and phosphorous treatment. Particularly, global removal (oxidation

$8+\mathrm{MBR}$ ) of some recalcitrant compounds such as DCF or FUR, and in a lesser extend CBZ were

9 improved comparing with the MBR without oxidation step. The observed decrease in toxicity of the treated pharmaceutical solutions corroborates pharmaceutical removal and indicates negligible toxicity of the by-products formed. Comparing with a sequential association of biological process and photooxidation process usually described in the literature, this innovative concept is expected to be more compact and less expensive and is very promising for an efficient removal of pharmaceuticals in wastewater.

\section{Acknowledgements}

This work was supported by the Program "SUDOE” on the project Innovec'EAU 2016-19 under award number SUDOE SOE1/P1/F0173. We thank R. Garcia, and J. J. Huc for their help in designing and building the demonstrator and Victor Pueyo for doing the analysis. 


\section{References}

1. Patel M, Kumar R, Kishor K, Mlsna T, Pittman Jr CU, Mohan D. Pharmaceuticals of emerging concern in aquatic systems: chemistry, occurrence, effects, and removal methods. Chem rev 119(6), 3510-3673 (2019).

2. Couto CF, Lange LC, Amaral MC. Occurrence, fate and removal of pharmaceutically active compounds (PhACs) in water and wastewater treatment plants-A review. $J$ Water Process Eng 32:100927 (2019).

3. Gogoi A, Mazumder P, Tyagi VK, Chaminda GT, An AK, Kumar M. Occurrence and fate of emerging contaminants in water environment: a review. Groundw Sustain Dev 6:169-180 (2018).

4. Schröder P, Helmreich B, Škrbić B, Carballa M, Papa M, Pastore C, Dvarioniene J. Status of hormones and painkillers in wastewater effluents across several European states - considerations for the EU watch list concerning estradiols and diclofenac. Environ Sci Pollut Res 23(13):12835-12866 (2016).

5. Millanar-Marfa JMJ, Borea L, Hasan SW, de Luna, MDG, Belgiorno V, Naddeo V. Advanced membrane bioreactors for emerging contaminant removal and quorum sensing control, in Current Developments in Biotechnology and Bioengineering, ed by Mannina G, Pandey A, Larroche C, Yong $\mathrm{Ng} \mathrm{H}$ and Hao Ngo H. Elsevier, pp 117-147 (2020).

6. Mompelat S, Le Bot B, Thomas O. Occurrence and fate of pharmaceutical products and by-products, from resource to drinking water. Environ Int 35(5):803-814 (2009).

7. Verlicchi P, Al Aukidy M, Zambello E. Occurrence of pharmaceutical compounds in urban wastewater: removal, mass load and environmental risk after a secondary treatment-a review. $S c i$ Total Environ 429:123-155 (2012).

8. Clara, M, Strenn, B, Gans O, Martinez E, Kreuzinger N, Kroiss H. Removal of selected pharmaceuticals, fragrances and endocrine disrupting compounds in a membrane bioreactor and conventional wastewater treatment plants. Water Res 39(19) 4797-4807 (2005).

9. Verlicchi P, Al Aukidy M, Galletti A, Petrovic M, Barceló D. Hospital effluent: investigation of the concentrations and distribution of pharmaceuticals and environmental risk assessment. Sci Total Environ 430:109-118 (2012).

10.Lacorte S, Luis S, Gómez-Canela C, Sala-Comorera T, Courtier A, Roig B, Oliveira-Brett AM, Joannis-Cassan C, Aragonés JI, Poggio L, Noguer T, Lima L, Barata C, Calas-Blanchard Pharmaceuticals released from senior residences: occurrence and risk evaluation. Environ Sci Pollut Res 25(7):6095-6106 (2018).

11.Rivera-Utrilla J, Sánchez-Polo M, Ferro-García MÁ, Prados-Joya G, Ocampo-Pérez R. Pharmaceuticals as emerging contaminants and their removal from water. A review. Chemosphere 93(7):1268-1287 (2013).

12.Luo Y, Guo W, Ngo HH, Nghiem LD, Hai FI, Zhang J, Liang S, Wang XC. A review on the occurrence of micropollutants in the aquatic environment and their fate and removal during wastewater treatment. Sci Total Environ 473:619-641 (2014).

13.Prieto-Rodríguez L, Oller I, Klamerth N, Agüera A, Rodríguez EM, Malato S. Application of solar AOPs and ozonation for elimination of micropollutants in municipal wastewater treatment plant effluents. Water Res 47(4):1521-1528 (2013).

14. Oller I, Malato S, Sánchez-Pérez J. Combination of advanced oxidation processes and biological treatments for wastewater decontamination-a review. Sci Total Environ 409(20): 4141-4166 (2011).

15.Kanakaraju D, Glass BD, Oelgemöller M. Advanced oxidation process-mediated removal of pharmaceuticals from water: A review. J Environ Manage 219:189-207 (2018).

16. Monteil H, Péchaud Y, Oturan N, Oturan M. A. A review on efficiency and cost effectiveness of electro-and bio-electro-Fenton processes: application to the treatment of pharmaceutical pollutants in water. Chem Eng J 376:119577 (2019).

17.Janin T, Goetz V, Brosillon S, Plantard G. Solar photocatalytic mineralization of 2,4-dichlorophenol and mixtures of pesticides: kinetic model of mineralization. Sol Energy 87:127-135 (2013).

18. Brienza M, Ahmed MM, Escande A, Plantard G, Scrano L, Chiron S, Goetz V. Use of solar advanced oxidation processes for wastewater treatment: Follow-up on degradation products, acute toxicity, genotoxicity and estrogenicity. Chemosphere 148:473-480 (2016). 
19.Mahmoud WM, Rastogi T, Kümmerer K. Application of titanium dioxide nanoparticles as a photocatalyst for the removal of micropollutants such as pharmaceuticals from water. Cur Opin Green and Sustain Chem 6:1-10 (2017).

20. Yahiat S, Fourcade F, Brosillon S, Amrane A. Removal of antibiotics by an integrated process coupling photocatalysis and biological treatment-case of tetracycline and tylosin. Int Biodeter Biodegr 65(7):997-1003 (2011).

21.Almomani F, Bhosale R, Kumar A, Khraisheh M. Potential use of solar photocatalytic oxidation in removing emerging pharmaceuticals from wastewater: A pilot plant study. Sol Energy 172:128-140 (2018).

22.Ahmed MB, Zhou JL, Ngo HH, Guo W, Thomaidis NS, Xu J. Progress in the biological and chemical treatment technologies for emerging contaminant removal from wastewater: a critical review. $J$ Hazard Mater 323:274-298 (2017).

23. Mohajerani M, Mehrvar M, Ein-Mozaffari F. An overview of the integration of advanced oxidation technologies and other processes for water and wastewater treatment. Int J Eng 3(2):120-46 (2009).

24.Akpotu S O, Oseghe E O, Ayanda OS, Skelton AA, Msagati TA, Ofomaja AE. Photocatalysis and biodegradation of pharmaceuticals in wastewater: effect of abiotic and biotic factors. Clean Technol Environl 1-21 (2019).

25.Laera G, Chong MN, Jin B, Lopez,A. An integrated MBR-TiO2 photocatalysis process for the removal of Carbamazepine from simulated pharmaceutical industrial effluent. Bioresour Technol, 102(13):7012-7015 (2011).

26.Kanakaraju D, Glass BD, Oelgemöller M. Titanium dioxide photocatalysis for pharmaceutical wastewater treatment. Environ Chem Lett 12(1):27-47 (2014).

27.Kacem M, Plantard G, Brienza M, Goetz V. Continuous-Flow Aqueous System for Heterogeneous Photocatalytic Disinfection of Gram-Negative Escherichia coli. Ind Eng Chem Res 56(51):1500115007 (2017).

28. Seira J, Sablayrolles C, Montréjaud-Vignoles M, Albasi C, Joannis-Cassan C. Elimination of an anticancer drug (cyclophosphamide) by a membrane bioreactor: Comprehensive study of mechanisms. Biochem Eng J 114:155-163 (2016).

29.American Public Health Association, Eaton, A. D., American Water Works Association \& Water Environment Federation. Standard methods for the examination of water and wastewater. Washington, D.C: APHA-AWWA-WEF (2005).

30.Test No. 301: Ready Biodegradability. OECD Publishing; 1992. doi:10.1787/9789264070349-en.

31.Gómez-Canela C, Sala-Comorera T, Pueyo V, Barata C, Lacorte S Analysis of 44 pharmaceuticals consumed by elderly using liquid chromatography coupled to tandem mass spectrometry. $J$ Pharmaceut Biomed Anal 168:55-63 (2019).

32.Raldúa D, André M, Babin PJ. Clofibrate and gemfibrozil induce an embryonic malabsorption syndrome in zebrafish. Toxicol Appl Pharm 228:301-314 (2008).

33.Besha AT, Gebreyohannes AY, Tufa RA, Bekele DN, Curcio E, Giorno L. Removal of emerging micropollutants by activated sludge process and membrane bioreactors and the effects of micropollutants on membrane fouling: A review. J Environ Chem Eng 5(3):2395-2414 (2017).

34.Meng F, Gao G, Yang TT, Chen X, Chao Y, Na G, Huang LN. Effects of fluoroquinolone antibiotics on reactor performance and microbial community structure of a membrane bioreactor. Chem Eng $J$ 280:448-458 (2015).

35.Meng F, Wang Z, Li, Y. Cure of filament-caused MBR fouling in the presence of antibiotics: taking ciprofloxacin exposure as an example. Ind Eng Chem Res 51(42):13784-13791(2012).

36.Radjenović J, Petrović M. Barceló D. Fate and distribution of pharmaceuticals in wastewater and sewage sludge of the conventional activated sludge (CAS) and advanced membrane bioreactor (MBR) treatment. Water Res 43(3):831-841 (2009).

37. Tadkaew N, Hai F I, McDonald JA, Khan SJ, Nghiem LD. Removal of trace organics by MBR treatment: the role of molecular properties. Water Res 45(8):2439-2451 (2011).

38.Kim M, Guerra P, Shah A, Parsa M, Alaee M, Smyth SA. Removal of pharmaceuticals and personal care products in a membrane bioreactor wastewater treatment plant. Water Sci Technol 69(11):22212229 (2014). 


\section{Park J, Yamashita N, Park C, Shimono T, Takeuchi DM, Tanaka H. Removal characteristics of pharmaceuticals and personal care products: comparison between membrane bioreactor and various biological treatment processes. Chemosphere 179:347-358 (2017).}


Table 1. Comparison of mean values of sludge characteristics of continuous MBR before and after 2 addition of native pharmaceuticals (MBR_1) or pre-oxidized pharmaceuticals (MBR_2) during 15 3 days. (Pharmaceuticals: IBU, DCF, CBZ, LEV, AMY, PAR and FUR at $40 \mu \mathrm{g} \cdot \mathrm{L}^{-1}$ in synthetic wastewater). 4 TSS: total suspended solid; VSS: volatile suspended solid; COD: chemical oxygen demand; TN: total 5 nitrogen; TP: total phosphorous.

6

MBR 1

MB R_2

\begin{tabular}{lcccc}
\hline & \multicolumn{2}{c}{ MBR_1 } & \multicolumn{2}{c}{ MB R_2 } \\
& \multicolumn{2}{c}{ Native pharmaceutical addition } & Pre-oxidized pharmaceutical addition \\
\hline & $\begin{array}{c}\text { Before adding } \\
\text { micropolluants }\end{array}$ & $\begin{array}{c}\text { After adding } \\
\text { micropolluants }\end{array}$ & $\begin{array}{c}\text { Before adding } \\
\text { micropolluants }\end{array}$ & $\begin{array}{c}\text { After adding } \\
\text { micropolluants }\end{array}$ \\
\hline TSS (g.L-1) & $3.2 \pm 0.2$ & $4.4 \pm 1$ & $2.9 \pm 0.1$ & $3.3 \pm 0.3$ \\
\hline VSS/TSS (\%) & $75 \pm 4$ & $74 \pm 7$ & $77 \pm 6$ & $75 \pm 8$ \\
\hline COD removal (\%) & $89.2 \pm 2.2$ & $89.2 \pm 1.7$ & $90.9 \pm 0.8$ & $92.9 \pm 1$ \\
\hline TN removal (\%) & $12.3 \pm 5.8$ & $23.6 \pm 5.7$ & $41.5 \pm 6.2$ & $38.2 \pm 4.1$ \\
\hline TP removal (\%) & $99.8 \pm 0.1$ & $99.8 \pm 0.1$ & $99.8 \pm 0.1$ & $99.8 \pm 0.1$ \\
\hline
\end{tabular}


1 Table 2. Mean apparent removal efficiencies in continuous MBR for a cocktail of pharmaceuticals

2 without pre-oxidation (MBR_1) or with pre-oxidation at a flux density of 5 W.m-2 (MBR_2)

3

4

5

6

\begin{tabular}{|c|c|c|c|c|c|c|c|c|}
\hline & & IBU & DCF & CBZ & FUR & AMY & LEV & PAR \\
\hline \multirow{2}{*}{$\begin{array}{l}\text { Without } \\
\text { pharmaceutical } \\
\text { pre-oxidation }\end{array}$} & $\begin{array}{l}\text { MBR_1 } \\
\text { (Figure 1. Exp (1) }\end{array}$ & $97 \pm 6 \%$ & $12 \pm 10 \%$ & $<0 \%$ & $1 \pm 30 \%$ & $100 \pm 0 \%$ & $46 \pm 27 \%$ & $98 \pm 3 \%$ \\
\hline & Literature range & $73 / 100^{5,37,38}$ & $0.2 / 87^{5,37}$ & $-42 / 51^{5,37,38}$ & $65^{38,39}$ & Not found & Not found & $>95^{5,37}$ \\
\hline \multirow{3}{*}{$\begin{array}{l}\text { With } \\
\text { pharmaceutical } \\
\text { pre-oxidation }\end{array}$} & $\begin{array}{l}\text { Oxidation } \\
\text { (Figure 1. Exp. 2) }\end{array}$ & nd & $3 \%$ & $7 \%$ & $0 \%$ & $10 \%$ & $8 \%$ & $36 \%$ \\
\hline & $\begin{array}{l}\text { MBR_2 } \\
\text { (Figure 1. Exp. 3) }\end{array}$ & nd & $45 \pm 13 \%$ & $<0 \%$ & $44 \pm 9 \%$ & $74 \pm 10 \%$ & $84 \pm 2 \%$ & $97 \pm 5 \%$ \\
\hline & $\begin{array}{l}\text { Oxidation + MBR_2 } \\
\text { (Figure 1. Exp. } 2+3 \text { ) }\end{array}$ & nd & $47 \%$ & $3 \%$ & $44 \%$ & $79 \%$ & $85 \%$ & $98 \%$ \\
\hline
\end{tabular}

7 
1 Figure 1. Experiments of this study (on the left) to demonstrate the feasibility of an innovative hybrid 2 process coupling a MBR and a photocatalytic oxidation process (on the right) for an efficient removal 3 of pharmaceutical micropollutants. $\mathrm{OMP}=$ organic micropollutants; $\mathrm{OMP}_{\mathrm{ox}}=$ oxidized

4 micropollutants; $\mathrm{Q}$ = flow rate; $\mathrm{IN}$ = inlet; $\mathrm{OUT}=$ outlet; $\mathrm{OX}=$ oxidized

5

$$
6
$$

1(

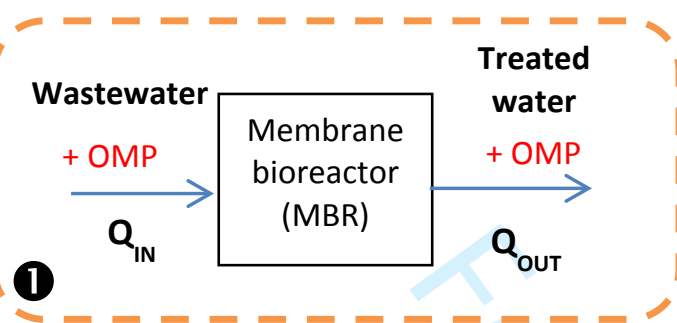

(3) $\stackrel{\mathrm{Q}_{\mathrm{IN}}}{\longrightarrow}$
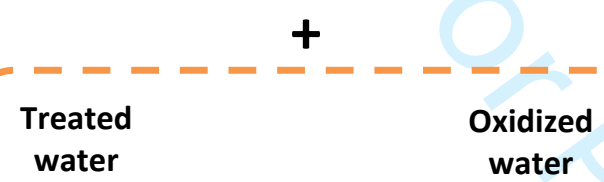

2
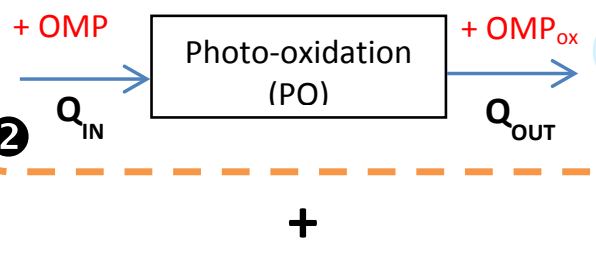

\section{Oxidized}

I OMPox

Membrane bioreactor (MBR)

water

$a_{\text {out }}$

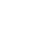

Innovative concept of a hybrid process between a biological process and a photooxidation process

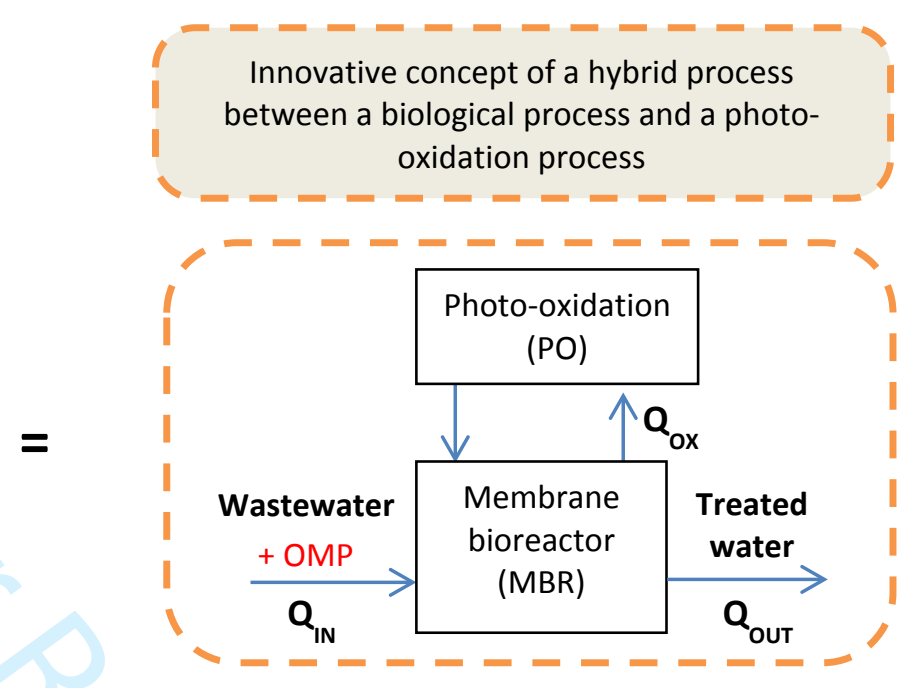


1 Figure 2. Scheme of the photoreactor consisting of a window (4) and a UV panel (5). The flow rate is 2 controlled by a peristaltic pump (1). A centrifugal pump (3) allows to feed the loop of recirculation $3(2)$.

6

7

8

9

10

11

12

13

14

15

16

17

18

19

20

21

22

23

24

25

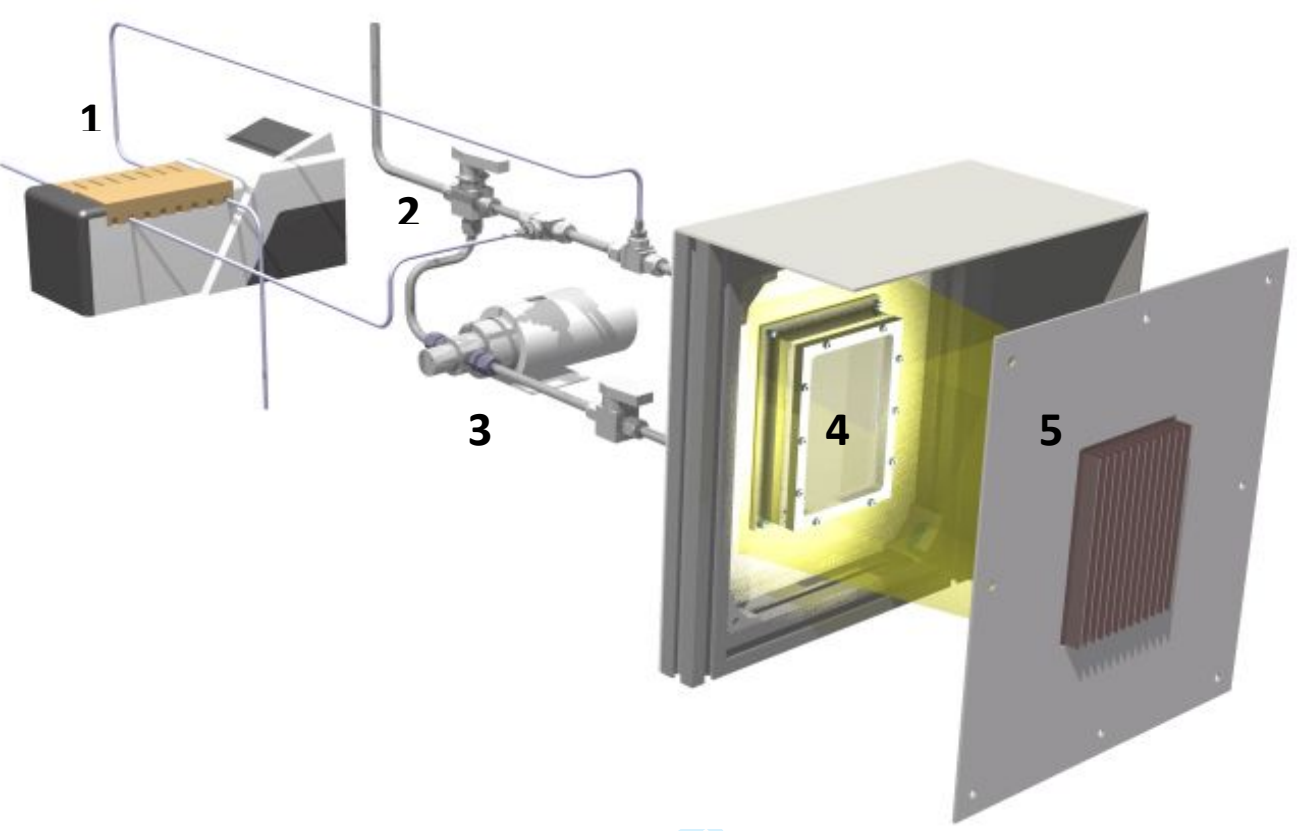

60 
1 Figure 3: Scheme of the continuous 20-L membrane bioreactor (MBR). Experiments were carried out 2 in two phases: during the first phase (phase I) the MBR was fed only with synthetic wastewater 3 without micropolluant and during the second one (phase II) a cocktail of micropollutants was added 4 together with the synthetic wastewater.

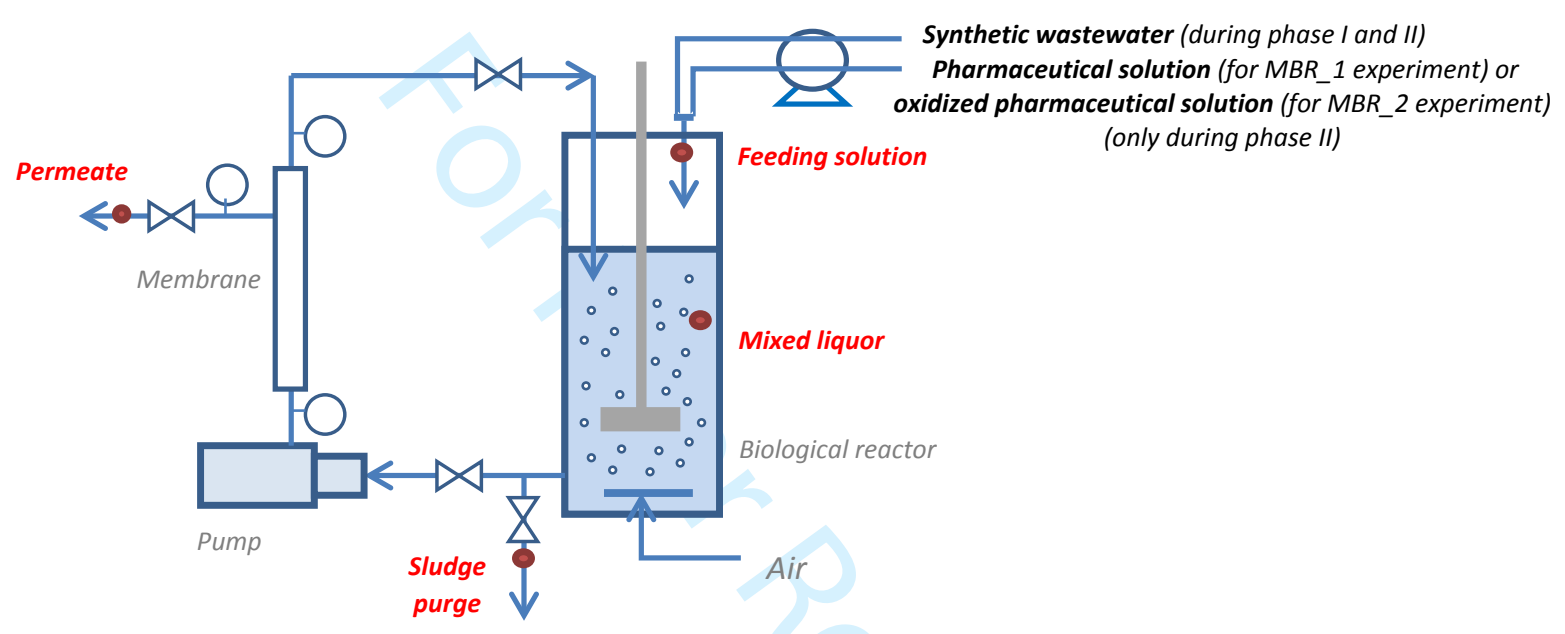


1 Figure 4. Photo-oxidation removal efficiency (RE), biodegradability and toxicity for IBU, DCF and CBZ alone (left)

2 or in cocktail (right) at $10 \mathrm{mg} \cdot \mathrm{L}^{-1}\left(/ / / /\right.$ before oxidation; $\quad$ after oxidation at $\mathrm{I}=10 \mathrm{~W} \cdot \mathrm{m}^{-2}$ )

3

4

5

6

7

8

9

10

22

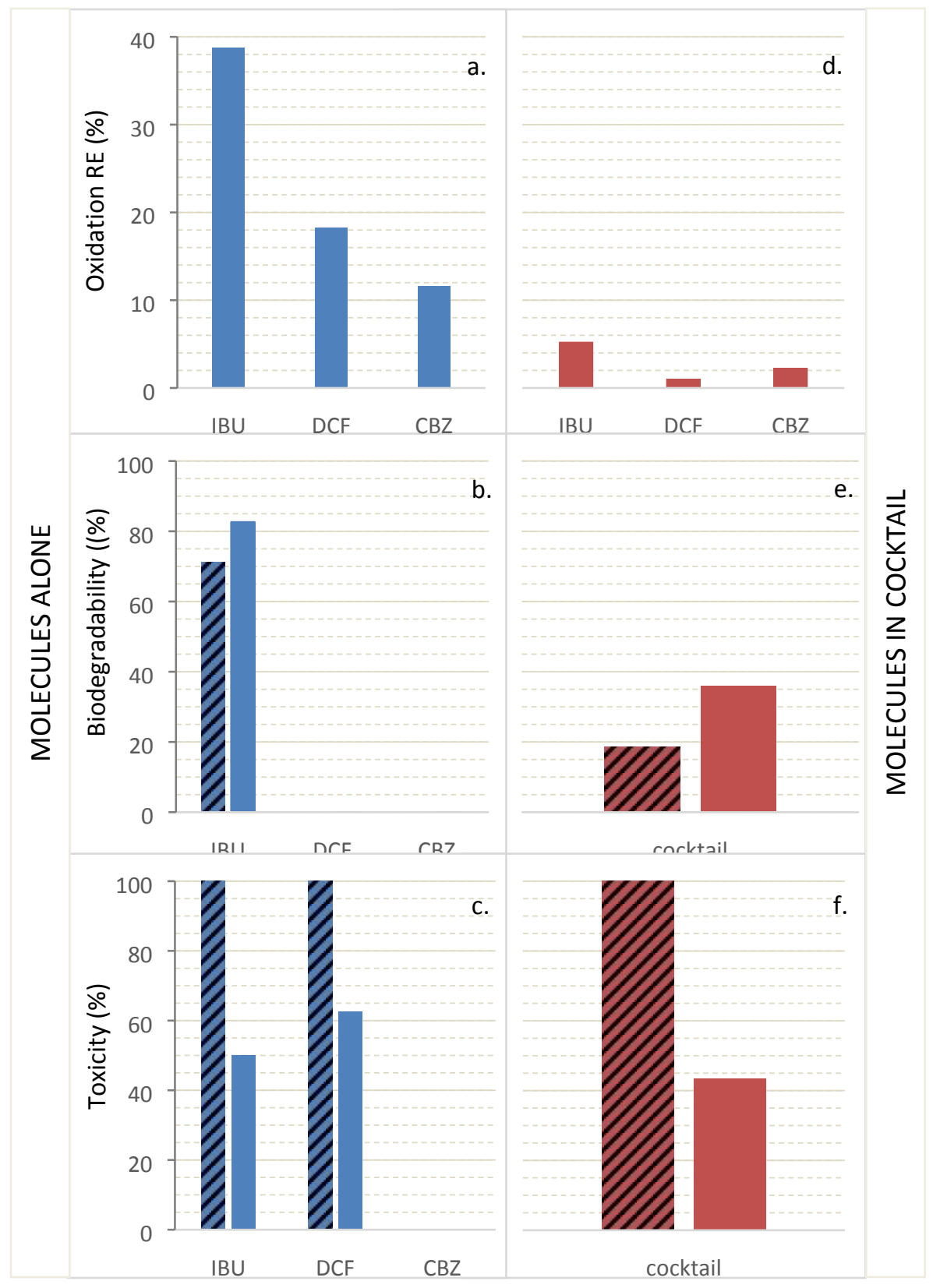


1 Figure 5: Effect of flux density (I) on photo-oxidation removal efficiency of IBU ( $\downarrow$ ), DCF ( $\square$ ) and CBZ

$2(\triangle)$, biodegradability $(O)$ and toxicity $(X)$ of a cocktail solution of IBU, CBZ and DCF at 10 mg. $L^{-1}$ each 3

4

5

6

7
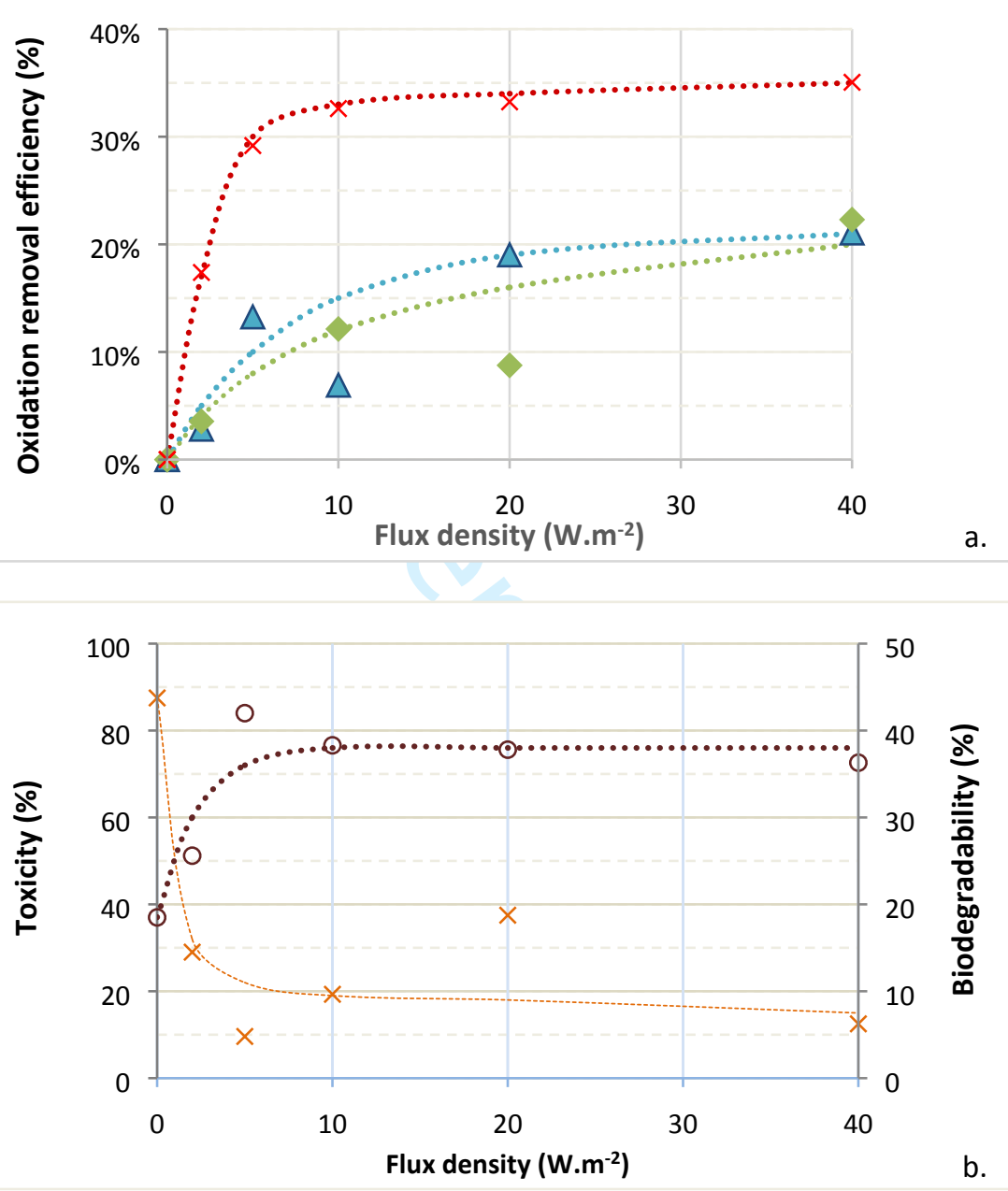

9 